\section{Italians demand a radical reform of grant evaluation}

Munich. More than 60 Italian biomedical scientists have sent a joint petition to the charities that sponsor biomedical research urging them to introduce a fairer system for allocating research funds, and in particular to adopt internationally recognized standards for evaluating grant applications.

Many of those who have signed the petition say they hope that the introduction of such changes by charities could influence state funding bodies to adopt the same procedures, but that the independent status of the charities should make it easier for them to make the first move.

At present, charities tend to follow the same assessment procedures as the National Research Council (CNR), whose 15 committees, each made up

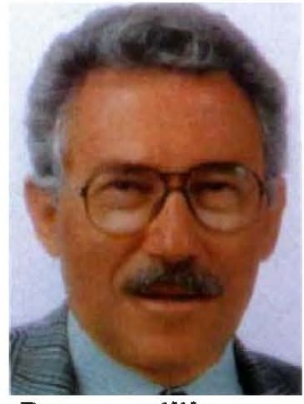

Romeo: petitioner. which projects to fund, but are under no obligation to consult outside experts.

Many critics claim that this procedure allows decisions to be excessively influenced by personal relationships, and encourages money to be spread relatively thinly across too many research groups in order to keep everyone happy. They also criticize the CNR for its lack of transparency, as the council does not always specify the criteria on which funding decisions are made, nor does it publish a list of grants awarded.

Giovanni Romeo, professor of molecular genetics at the Giannina Gaslini Institute in Genoa, who is leading the campaign to introduce a more open refereeing system, says that charities do not have to follow the CNR's example just because it is familiar.

The petition signed by Romeo and others makes three demands: that all grant applications should be peer reviewed by independent referees, 51 per cent coming from outside Italy; that the distribution of funds should be made public, with scientific reports published at the end of the funding period; and that the members of scientific committees should be elected for a nonrenewable five-year term.

Italy's two main charities for funding biomedical research are the Associazione Italiana per la Ricerca sul Cancro (AIRC, the Italian cancer research association) and Telethon, whose television appeals fund research into genetic - and particularly neuromuscular - disorders. Both meet some of these criteria; in contrast, says Romeo, most smaller charities meet none of them.
The AIRC, which distributed L38 billion (US\$22.8 million) last year for projects and fellowships, already publishes a list of the projects it funds. But Giuseppe Della Porta, its scientific director, says he does not agree that the charity needs to introduce compulsory peer review. He says that the AIRC scientific committee, whose 14 members are changed at irregular intervals, can make the necessary decisions on its own, and should be left to choose whether to use outside referees. An application to extend a grant goes to a single committee member, and new applications go to two.

Della Porta sees no reason for change. "We know each other, and we know the importance of certain groups," he says, adding that the main need is to rotate committee members. $\mathrm{He}$ is also opposed to seeking advice from foreign scientists. "Italy has enough scientists, if committee members want to use them," he says.

Telethon, which has distributed L28 billion in the three years since it was established, is more outward looking, with half of its scientific committee of ten working abroad. Each grant application goes to three members; many applications are sent to external referees.

"The petition is a recommendation, not a criticism", says Edoardo Boncinelli, head of the laboratory of the molecular biology of development at the San Rafaelle Institute of Research in Milan. "Many of the charities do very good work; but it could be improved by a proper peer review system".

Boncinelli criticizes the government for not insisting that the research it funds is appropriately assessed. Before the recent resignation of the government, Umberto Colombo, the research minister, had taken steps to change this, promising that in future three per cent of each award would be used for refereeing and evaluation, and that a formal international refereeing system would be introduced for all state-funded research. Whether these changes will now be carried through is in doubt.

Enrico Garaci, head of the CNR, says he is enthusiastic about Colombo's ideas. But he adds that he does not consider the introduction of compulsory peer review to be one of CNR's priorities. Frustrated Italian scientists may draw comfort from an example which proves that such a move, even in Italy, is indeed possible. Under a system introduced in 1989 by Gian Rossi of the Istituto Superiore di Sanita, the Italian AIDS project, which receives $\mathrm{L} 30$ billion a year from the ministry of health, operates a strict international peer review system for grant applications, and publishes detailed accounts every year.

\section{Ariane still riding high despite launch failure}

Kourou. Arianespace, the French space agency (CNES) and the European Space Agency (ESA) have launched a joint investigation into the failure of the 63rd flight of the Ariane rocket which crashed into the Atlantic last week carrying two satellites insured for US\$356 million.

The early phases of the rocket's flight went smoothly after it took off from the Guiana Space Centre at 18.37 local time on 24 January. In particular, officials responsible for the launch appeared relieved when the cryogenic third stage ignited successfully 5 minutes 47 seconds after take-off; three of Ariane's five past failures occurred because the third stage did not ignite (the other two failures involved the first stage).

But instead of burning for ten minutes, the stage stopped after just 80 seconds, at a height of $215 \mathrm{~km}$. The rocket's ascending trajectory displayed on screens in the Jupiter control room took on an alarming downward path, and the end was inevitable.

The investigation should be completed within the next two weeks, and will focus on a sudden increase in temperature of a bearing of the liquid oxygen part of the liquid oxygen/hydrogen turbopump which was noticed 20 seconds before the pump apparently jammed.

The pump is one of the most susceptible items of Ariane technology. Weighing just $30 \mathrm{~kg}$, it rotates at 60,000 r.p.m. on the hydrogen side and 13,000 r.p.m. on the oxygen side. Moreover, it must keep liquid hydrogen at $-251^{\circ} \mathrm{C}$ and liquid oxygen at $-184^{\circ} \mathrm{C}$, while the temperature in the adjacent combustion chamber is over $1,500{ }^{\circ} \mathrm{C}$.

Arianespace has suspended its flight programme until it finds and corrects the cause of the accident. This may delay its plans to increase the frequency of launches to ten a year; Arianespace already has 37 launches, worth FFr 17 billion (US $\$ 2.9$ billion) on its order books up until 1997.

Insurance companies say any delay would reduce the income from successful launches, needed to offset the US\$356 million insurance claim for the lost Turksat 1-A and Eutelsat-II-5A satellites - the largest in the history of space. This represents a typical year's income for the space insurance industry, according to Faugére and Jutheau, the French insurance brokers handling the claim.

The company says that the accident has wiped out ten years of profits, and will cause premiums to increase. But the failure is unlikely to diminish customer confidence in the European launcher, which after 26 consecutive successes since its last failure in 1990 - caused by a rag left in the first stage - remains the world's most reliable launcher.

Declan Butler 